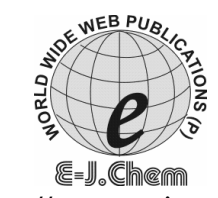

http://www.e-journals.net
ISSN: 0973-4945; CODEN ECJHAO

E-Journal of Chemistry

2009, 6(S1), S17-S20

\title{
Compatibility Study of Lamivudine with Various Cellulose Polymers
}

\author{
P. NARAYANA RAJU*, K. PRAKASH ${ }^{\S}$ and M. LAKSHMI NARASU \\ *KLR College of Pharmacy, Paloncha, Khamman Dist., Andhrpradesh, India. \\ ${ }^{\S}$ Faculty of Pharmacy, $7^{\text {th }}$ April University, Zawia, Libya. \\ Centre for Biotechnology, Institute of Science and Technology, \\ JNTU, Kukatpally, Hyderabad, Andhra Pradesh, India. \\ nrpadala@rediffmail.com
}

Received 2 April 2009; Accepted 5 June 2009

\begin{abstract}
For the development of any formulation, techniques such as thermal and isothermal stress testing were used to assess the compatibility of drug with excepients. Differential scanning calorimetry (DSC) and FTIR were the common methods for the study of compatibility. Isothermal stress testing (IST) is also a method for the compatibility study during proto type formulation. In the present study drug excepient compatibility study of lamivudine was conducted with different controlled release polymers. The drug and polymer mixtures were stored at $50{ }^{\circ} \mathrm{C}$ for 2 weeks. The samples were then characterized using DSC, FTIR and UV spectrophotometric methods. The results show that lamivudine was compatible with the all the polymers used in the study. The polymers used in the present study were definitely incorporated in the extended release lamivudine formulation.
\end{abstract}

Keywords: Lamivudine, Compatibility, Polymers, IST, DSC, FTIR

\section{Introduction}

Drug excepient compatibility can alter the physicochemical properties and bioavailability of the drugs. This incompatibility there by affects its safety and/or efficacy. Study of the drug excepient compatibility is an important process in the development of the stable solid dosage form and it helps in the selection of right excepient. This increases the probability of developing a stable dosage form.

Despite of the importance of the drug excepient compatibility tests, there is no universally accepted protocol for this purpose. The term thermal analysis refers to the group of techniques in which physical property of a substance is measured as a function of temperature. Differential scanning calorimetry (DSC) technique involves the application of a 
heating or cooling signal to a sample and a reference. When the substance undergoes a thermal event, the difference in heat flow to sample and reference is monitored against time and temperature. As a result, energy associated with various thermal events ( $e g$ melting, glass transition temperature and crystallization etc.) can be evaluated ${ }^{1}$. This method can be extensively reported in the literature for the testing of the compatibility of the excepients with number of $\operatorname{drugs}^{2-7}$. Infrared spectroscopy is a technique based on the vibrations of the atoms of a molecule. An infrared spectrum is commonly obtained by passing infrared radiation through a sample and determining what fraction of the incident radiation is absorbed at a particular energy. The energy at which any peak in an absorption spectrum appears corresponds to the frequency of a vibration of a part of a sample molecule ${ }^{8}$. UV spectrophotometric method is common analytical techniques used to determine the drug content of most of the drugs.

In the present study, the drug excepient compatibility of the lamivudine with various cellulose polymers was determined by isothermal stress testing (IST) as a part of an ongoing project on the development of extended release formulation of lamivudine. DSC, FTIR and UV spectrophotometric methods were used for the characterization study.

\section{Experimental}

Lamivudine was obtained as a gift sample from Alkem laboratories Ltd (Mumbai, India). Cellulose acetate phthalate (CAP) was obtained from GM Chemicals, India, cellulose acetate butyrate $(\mathrm{CAB})$ was obtained from Eastman chemical company, USA, ethyl cellulose (EC) was obtained from DOW Chemical Company, USA and hydroxy propyl methyl cellulose acetate phthalate (HPMCP) was obtained from SHIN-Etsu, Japan. All other chemicals and reagents used in the study were of analytical grade.

The drug and polymer mixtures of lamivudine with various polymers prepared at 1:2 ratio. The drug and different polymers were individually weighed in a $10 \mathrm{~mL}$ glass vial and mixed on a vortex mixer for $2 \mathrm{~min}$. In each of the vials, $10 \%$ of the water was added and the drug-excepient blend was further mixed. Each vial was sealed Teflon-lined screw cap and stored at $50{ }^{\circ} \mathrm{C}$ for 2 weeks. These samples were periodically examined for any change of unusual color change.

\section{Characterization by UV spectrophotometer}

The samples after 2 weeks were withdrawn from storage and analyzed by UV spectrophotomer. The drug content was determined at initial and stored samples in triplicate. An accurately weighed amount of the drug-polymer mixture was taken and suitably dissolved under sonication (Power sonic 505, HWASHIN technology co) in $\mathrm{pH} 6.8$ phosphate buffer and filtered through $0.45 \mu$ (Millipore) filters. The sample was analyzed after making appropriate dilutions using UV spectrophotometer (Schimadzu, UV-1700 E 23) at $271 \mathrm{~nm}$ against blank

\section{Fourier transforms infrared radiation measurement (FT-IR)}

The FT-IR spectra acquired were taken from dried samples. A FT-IR (Thermo Nicolet 670 spectrometer) was used for the analysis in the frequency range between 4000 and $400 \mathrm{~cm}^{-1}$, with $4 \mathrm{~cm}^{-1}$ resolution. The results were the means of 6 determinations. A quantity equivalent to $2 \mathrm{~g}$ of pure drug and matrix tablets were selected separately.

\section{Differential scanning calorimetry (DSC) study}

Differential scanning calorimetry (DSC) study of matrix tablets was performed using a Diamond DSC (Mettler Star SW 8.10) to determine the drug excepient compatibility study. The analysis was performed at a rate $5{ }^{0} \mathrm{C} \mathrm{min}^{-1}$ from 50 to $200{ }^{0} \mathrm{C}$ temperature range under nitrogen flow of $25 \mathrm{~mL} \mathrm{~min}^{-1}$. 


\section{Results and Discussion}

\section{Drug content estimation}

The drug and polymer mixture was physically observed at different intervals. No characteristic color change was observed. The assay of the drug polymer mixtures were found good. Assay value of 99.12 to 100.1 was observed at initial. Good correlation was observed with the samples of drug polymer mixtures stored at $50{ }^{\circ} \mathrm{C}$ for 2 weeks. This clearly indicates the stable nature of the lamivudine with cellulose polymers (Table 1).

Table 1. Drug content of lamivudine at initial and storage at $50{ }^{\circ} \mathrm{C}$ for 2 weeks.

\begin{tabular}{lcccc}
\hline & Drug-CAP & Drug-CAB & Drug-EC & Drug-HPMCP \\
\hline Initial & 99.33 & 99.56 & 99.12 & 100.1 \\
$50{ }^{\circ} \mathrm{C}$ for 2 weeks & 99.11 & 99.02 & 99.32 & 99.11 \\
\hline
\end{tabular}

Fourier transforms infrared radiation measurement (FT-IR)

The characteristic band peaks acquired were taken from the prepared drug-polymer mixtures. The interaction study between drug and polymer was evaluated. The characteristics peak of the carbonyl group present in the cystedine nucleus at $1650 \mathrm{~cm}^{-1}$, a band of peaks at 3325 and $3203 \mathrm{~cm}^{-1}$ owing to amino and hydroxyl groups. Peaks at 1285 and $1160 \mathrm{~cm}^{-1}$ owing to asymmetrical and symmetrical stretching of $\mathrm{C}-\mathrm{O}-\mathrm{C}$ system present in the oxathiolane ring conforms the stable nature of the drug in the polymer mixture (Figure 1).

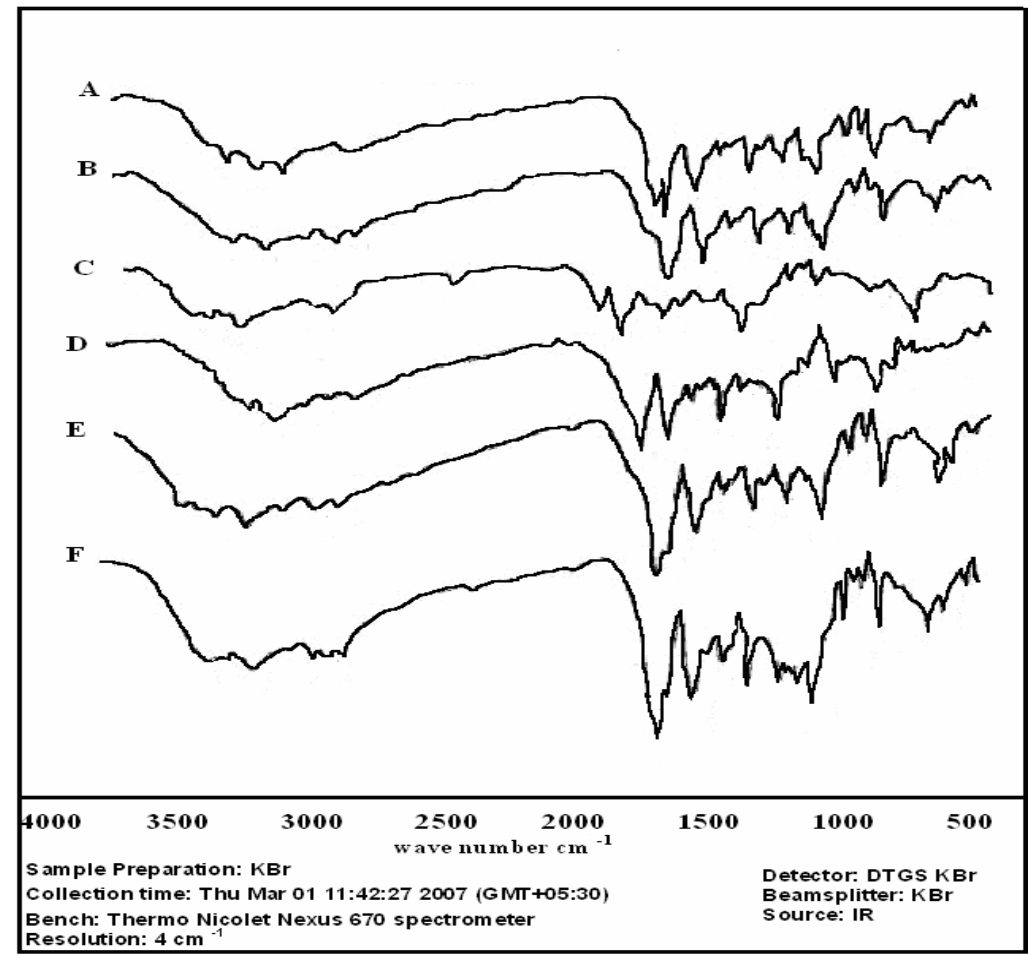

Figure 1. FTIR Spectra of pure (A) Lamivudine at initial, (B) Lamivudine at $50{ }^{\circ} \mathrm{C}$ - 2 weeks (C) Lamivudine-CAP at $50{ }^{\circ} \mathrm{C}-2$ weeks (D) Lamivudine-CAB at $50{ }^{\circ} \mathrm{C}-2$ weeks (E) Lamivudine-EC at $50{ }^{\circ} \mathrm{C}-2$ weeks (F) Lamivudine-HPMCP at $50{ }^{\circ} \mathrm{C}-2$ weeks. 


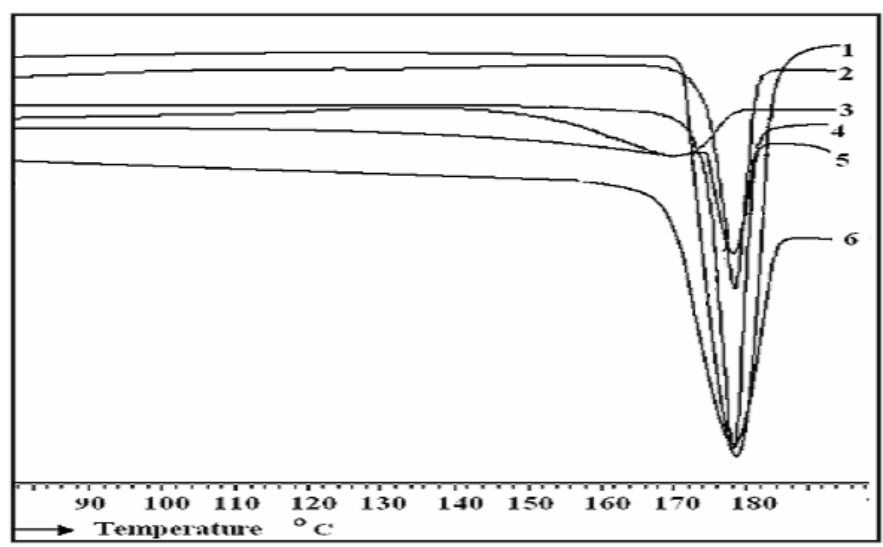

Figure 2. DSC thermograms of pure (1) Lamivudine at initial, (2) Lamivudine at $50{ }^{\circ} \mathrm{C}-2$ weeks (3) Lamivudine-CAP at $50{ }^{\circ} \mathrm{C}-2$ weeks (4) Lamivudine-CAB at $50{ }^{\circ} \mathrm{C}-2$ weeks (5) Lamivudine-EC at $50{ }^{\circ} \mathrm{C}-2$ weeks (6) Lamivudine-HPMCP at $50{ }^{\circ} \mathrm{C}-2$ weeks.

\section{Differential scanning calorimetry (DSC) study}

Differential scanning calorimetry (DSC) studies of drug-polymer mixtures were performed using a Diamond DSC (Mettler Star SW 8.10) to determine the drug excepient compatibility study. The analysis was performed at a rate $50 \mathrm{C} \mathrm{min}^{-1}$ from 500 to $2000{ }^{\circ} \mathrm{C}$ temperature range under nitrogen flow of $25 \mathrm{~mL} \mathrm{m^{-1 }}$. Thermograms of pure lamivudine showed sharp endothermic peak at $180{ }^{\circ} \mathrm{C}$. Similar peaks were obtained in the prepared drug-polymer mixtures. This clearly indicated the nil drug polymer interaction.

\section{Summary and conclusions}

No characteristic color change was observed during the storage at $50{ }^{\circ} \mathrm{C}$ for 2 weeks. Good correlation was observed at initial and during IST. This clearly indicates the stable nature of lamivudine with the cellulose polymers used in the preset study. FTIR study of the initial and IST clearly indicates the stable nature of the lamivudine. DSC study conform the stable nature of the lamivudine during isothermal stress testing. This study is defiantly useful for the preparation of lamivudine extended release formulations.

\section{Acknowledgement}

The authors are greatly acknowledging the Alchem Laboratories, Mumbai, India, for supply of lamivudine as gift sample. The authors are grateful to Indian Institute of Chemical Technology, Hyderabad, India for help in performing the characterization studies.

\section{References}

1. Araujo A A S, Stropirts S, Mercuri L P and Carvalho F M S, Int J Pharm., 2003, 260, 303.

2. Tonder E C V, Lotter A P and Botha S A, Drug Dev Ind Pharm., 1990, 16, 2125.

3. Venkatram S, Koholwane M and Wallis S H, Drug Dev Ind Pharm, 1995, 21, 847

4. Kandarapu R, Grover V, Chaweala H P S, Garg S, S T P Pharma Sci., 2001, 11, 449.

5. Mura P, Mandereroil A, Bramanti G, Furlanetto S and Pinzauti S, Int .J Pharm., 1995, 119, 71.

6. Mura P, Faucci M T, Mandereroil A, Bramanti G and Ceccareli L, J Pharma Biomed Anal., 1998, 18, 151.

7. Botha S.A, Lotter A.P, Drug Dev Ind Pharm., 1990, 16, 673.

8. Serajuddin A T M, Thakur A B, Ghoshal R N, Fakes M G, Ranadive S A, Morris K R, Varis S A, J Pharm Sci., 1999, 88(7), 696. 


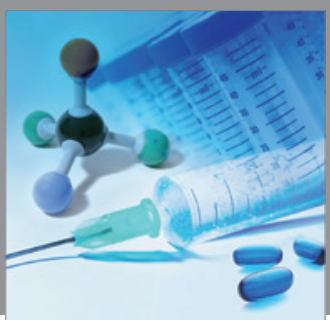

International Journal of

Medicinal Chemistry

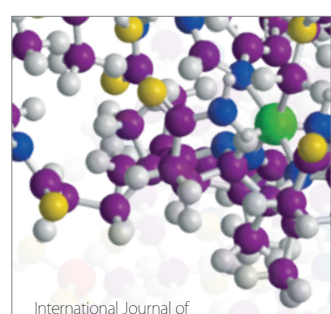

Carbohydrate Chemistry

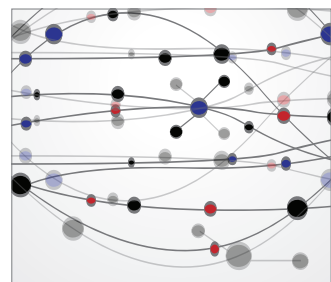

The Scientific World Journal
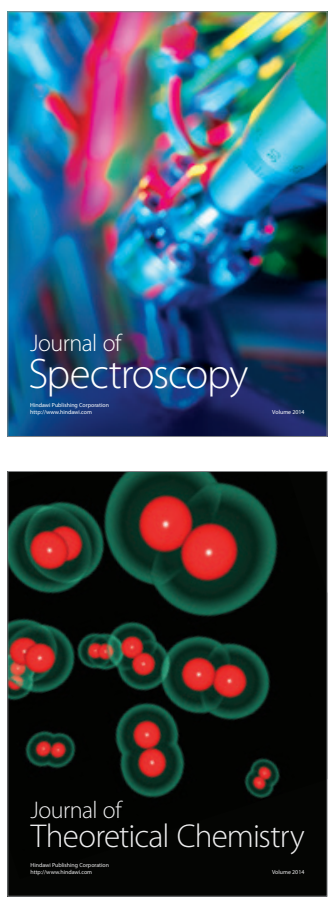
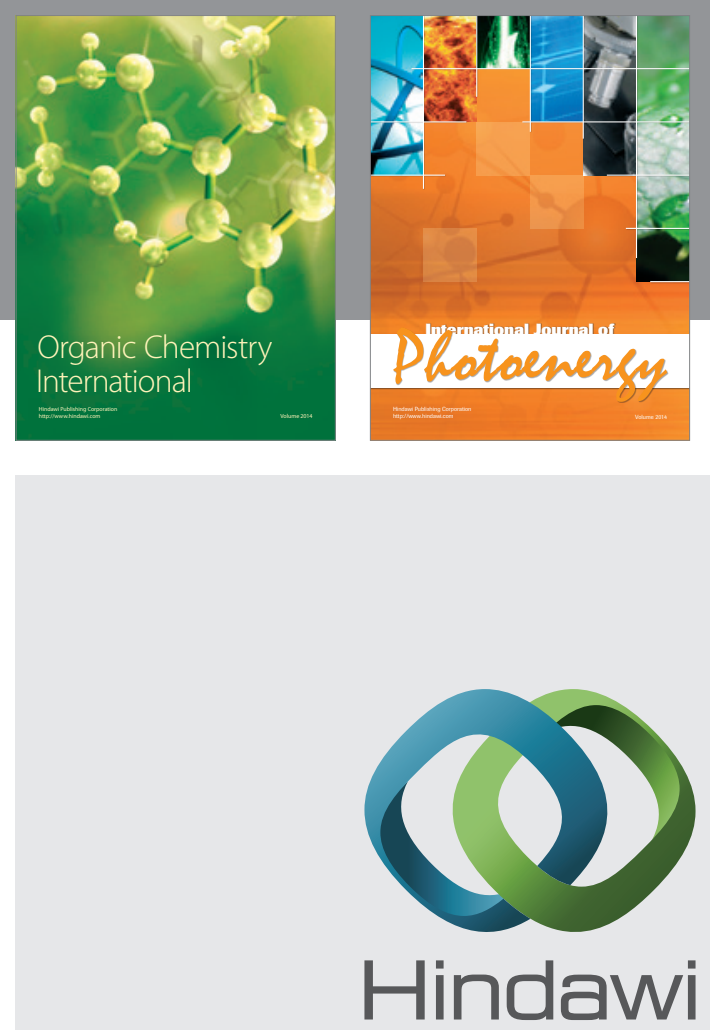

Submit your manuscripts at

http://www.hindawi.com
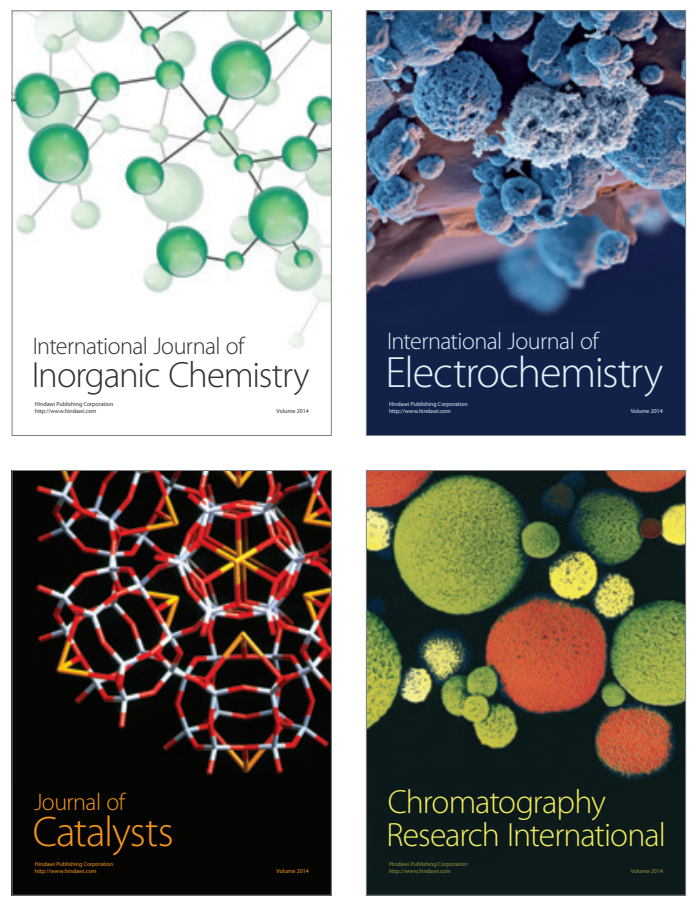
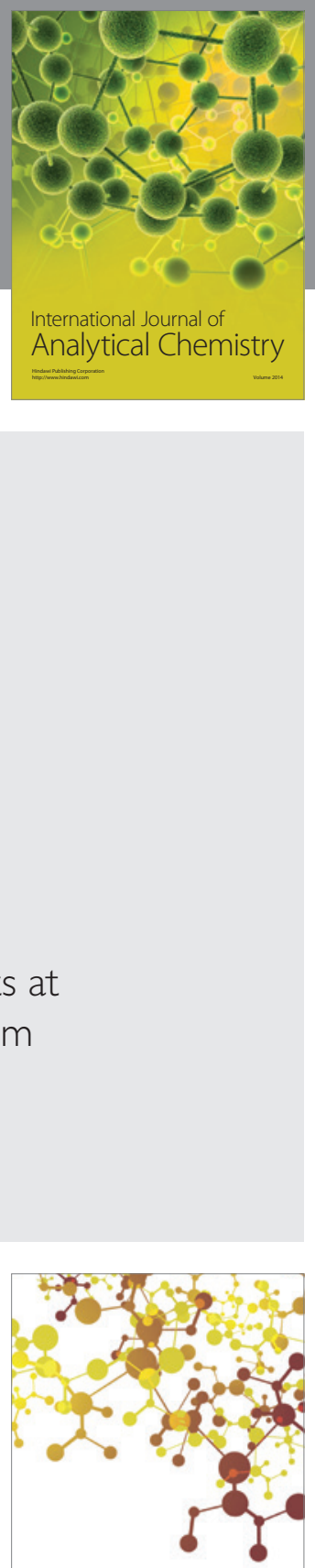

Journal of

Applied Chemistry
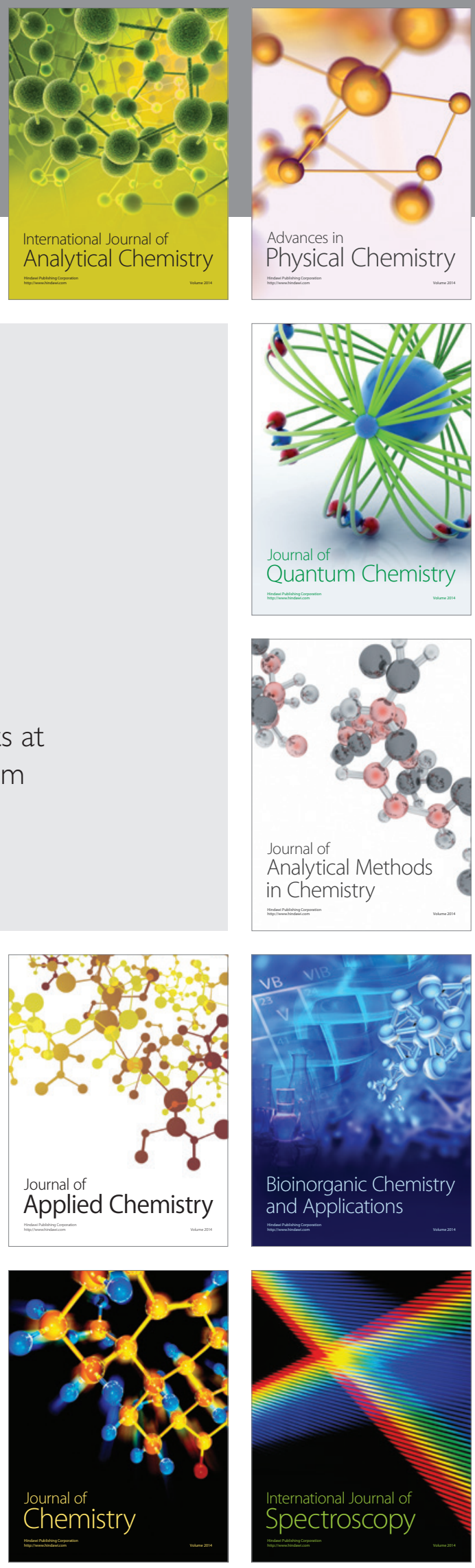